BNL-113672-2017-JA

\title{
The Role of Citric Acid in Perfecting Platinum Monolayer on Palladium Nanoparticles during the Surface Limited Redox Replacement Reaction
}

\author{
Shangqian Zhu, Jeffrey Yue, Xueping Qin, Zidong Wei, Zhixiu Liang, \\ Radoslav R. Adzic, Stanko R. Brankovic, Zheng Du, Minhua Shao
}

Submitted to Journal of Electrochemical Society

July 2016

Chemistry Department

Brookhaven National Laboratory

\author{
U.S. Department of Energy \\ USDOE Office of Science (SC), \\ Basic Energy Sciences (BES) (SC-22)
}

Notice: This manuscript has been authored by employees of Brookhaven Science Associates, LLC under Contract No. DE- SC0012704 with the U.S. Department of Energy. The publisher by accepting the manuscript for publication acknowledges that the United States Government retains a non-exclusive, paid-up, irrevocable, world-wide license to publish or reproduce the published form of this manuscript, or allow others to do so, for United States Government purposes. 


\section{DISCLAIMER}

This report was prepared as an account of work sponsored by an agency of the United States Government. Neither the United States Government nor any agency thereof, nor any of their employees, nor any of their contractors, subcontractors, or their employees, makes any warranty, express or implied, or assumes any legal liability or responsibility for the accuracy, completeness, or any third party's use or the results of such use of any information, apparatus, product, or process disclosed, or represents that its use would not infringe privately owned rights. Reference herein to any specific commercial product, process, or service by trade name, trademark, manufacturer, or otherwise, does not necessarily constitute or imply its endorsement, recommendation, or favoring by the United States Government or any agency thereof or its contractors or subcontractors. The views and opinions of authors expressed herein do not necessarily state or reflect those of the United States Government or any agency thereof. 


\title{
The Role of Citric Acid in Perfecting Platinum Monolayer on Palladium Nanoparticles during the Surface Limited Redox Replacement Reaction
}

Shangqian Zhu, ${ }^{\dagger, \#}$ Jeffrey Yue, ${ }^{\dagger, \#}$ Xueping Qin, ${ }^{\dagger}$ Zidong Wei, ${ }^{\ddagger}$ Zhixiu Liang, ${ }^{\prime}$ Radoslav R. Adzic, Stanko R. Brankovic, ${ }^{\Delta}$ Zheng Du, ${ }^{\$}$ Minhua Shao ${ }^{\dagger *}$

${ }^{\dagger}$ Department of Chemical and Biomolecular Engineering, The Hong Kong University of Science \& Technology, Clear Water Bay, Kowloon, Hong Kong

${ }^{\ddagger}$ College of Chemistry and Chemical Engineering, Chongqing University, 400044, PR China

' Chemistry Department, Brookhaven National Laboratory, Upton, NY 11973, USA

${ }^{\Delta}$ Department of Electrical and Computer Engineering, University of Huston, TX 77204, USA

$\$$ National Supercomputing Center in Shenzhen, Shenzhen, Guangdong, 518031, PR China

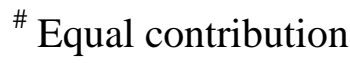

*kemshao@ust.hk

\begin{abstract}
$\mathrm{Cu}$-mediated-Pt-displacement method that involves the displacement of an underpotentially deposited (UPD) $\mathrm{Cu}$ monolayer by $\mathrm{Pt}$ has been extensively studied to prepare core-shell catalysts. It has been found that Pt clusters instead of a uniform Pt monolayer were formed in the gram batch synthesis. With a suitable surfactant, such as citric acid, the Pt shell could be much more uniform. In this study, the role of citric acid in controlling the Cu-Pt displacement reaction kinetics was studied by electrochemical techniques and theoretical approaches. It was found that citric acid strongly adsorbed on $\mathrm{Pd}, \mathrm{Pt}, \mathrm{Cu} / \mathrm{Pd}$, and Pt/Pd surfaces, especially in the double layer region in acid solutions. The strong adsorption of citric acid slowed down the Cu-Pt displacement reaction. The main characteristics of such strong interaction most likely arises from the $\mathrm{OH}$ groups in the citric acid molecule according to the molecular dynamics simulation results.
\end{abstract}

Keywords: Core-shell, monolayer, surfactant, fuel cells, density functional theory 


\section{Introduction}

Core-shell electrocatalysts consisting of a thin layer of Pt deposited on the surface of a lower cost nanoparticle, such as $\mathrm{Pd}$, have been considered as one of the promising candidates to replace $\mathrm{Pt} / \mathrm{C}$ at the cathode of proton exchange membrane fuel cells (PEMFCs). ${ }^{1-12}$ As only surface atoms actively participate in the oxygen reduction reaction (ORR), this approach can significantly enhance the utilization of Pt, i.e., lower the ratio of unexposed Pt atoms wasted inside of the particles. The core-shell structure can also provide significant benefits in cost reduction since the core is less expensive than Pt. In addition, the geometric and electronic effects induced by the underlying substrate can enhance the activity of the Pt shell for the ORR, leading to greater activity per mass of Pt than that expected based on utilization improvement alone. $^{13-15}$ Cu-mediated-Pt-displacement method that involves the displacement of an underpotentially deposited (UPD) Cu monolayer by Pt has been extensively studied to prepare core-shell catalysts since Adzic's pioneer work. ${ }^{2}$ In this method, the Cu monolayer deposited on the core (for example Pd) is displaced by Pt via a surface limited redox replacement (SLRR) reaction: $\mathrm{Pd} @ \mathrm{Cu}+\mathrm{PtCl}_{4}{ }^{2-} \rightarrow \mathrm{Pd} @ \mathrm{Pt}+\mathrm{Cu}^{2+}+4 \mathrm{Cl}^{-}$, as illustrated in Fig. 1. A wide variety of core-shell electrocatalysts consisting of different types of cores have been synthesized on a microgram scale on a rotating disk electrode (RDE) tip. ${ }^{4}$ For some core-shell catalysts, the Pt mass activities can be 10 times higher than that of Pt/C measured by RDE. ${ }^{\text {5, 16, } 17}$

Ideally, a uniform Pt monolayer is deposited on the core after all the $\mathrm{Cu}$ atoms are replaced. However, our previous study demonstrated that Pt clusters rather than a uniform Pt shell is formed on Pd nanoparticles (Fig. 1). The mechanism underlying this observation is that the SLRR process involves the electron transfer from the substrate ( $\mathrm{Pd}$ in this case) to $\mathrm{PtCl}_{4}{ }^{2-}$ ions, rather than direct electron exchange from $\mathrm{Cu}$. That means electrons generated anywhere on the surface can move freely through $\mathrm{Pd}$ substrate, reducing $\mathrm{PtCl}_{4}{ }^{2-}$ ions wherever their activity and surface energy are greatest. ${ }^{18}$ In other words, the Pt atom may not deposit on the same site left by the $\mathrm{Cu}$ dissolution, but rather on $\mathrm{Pt}$ that was already deposited on the core leading to the formation of Pt clusters. Due to the incomplete Pt coverage and low Pt usage, it is expected to have lower activity and stability than a perfect core-shell structure. Thus, to synthesize core-shell materials with good quality on a large scale, the key is to force the Pt atom to deposit on the surface of the core rather than on $\mathrm{Pt}$ atoms already deposited by manipulating the $\mathrm{Cu}-\mathrm{Pt}$ displacement reaction kinetics. 
We found that the coverage of Pt shell could be significantly improved by adding a certain additive in the Pt-Cu displacement solutions. ${ }^{5,}$ 19, 20 The Pt mass activity of Pd@Pt/C was improved by two times with the assistance of citric acid in the synthesis process. ${ }^{20}$ It should be noted that the undisclosed additive in Refs. 5 and 19 is also citric acid. The role of citric acid in perfecting the Pt shell on Pd substrate is unknown. In this study, the specific adsorption of citric acid on surfaces of Pt and Pd, and its effect on the Pt deposition were investigated by combining electrochemical techniques and Molecular Dynamics simulations.

\section{Experimental section}

\subsection{Electrochemistry}

Approximately $10 \mathrm{mg}$ of Pd/C (35\%, TKK) or Pt/C (46\%, TKK) was ultrasonically dispersed in a mixing solvent consisting of $10 \mathrm{~mL}$ of water, $5 \mathrm{~mL}$ of isopropanol, and $30 \mu \mathrm{L}$ of $5 \%$ Nafion (Aldrich) for $10 \mathrm{~min} .10 \mu \mathrm{L}$ of the suspension was deposited on a pre-cleaned glassy carbon rotating disk electrode (Pine Instruments) and allowed to dry in air. A leak-free Ag/AgCl (BASi) electrode calibrated by a reversible hydrogen electrode (RHE) in the corresponding electrolyte solution was used as the reference electrode. All the potentials in this study were reported against RHE. The working electrode was cycled between 0.02 ( 0.07 for Pd/C) and $1.2 \mathrm{~V}$ for 10 cycles in an Ar-saturated $0.1 \mathrm{M} \mathrm{HClO}_{4}$ (GFS Chemicals, Veritas double distilled) or $0.05 \mathrm{M} \mathrm{H}_{2} \mathrm{SO}_{4}$ (GFS Chemicals, Veritas double distilled) solution at $100 \mathrm{mV} \mathrm{s}^{-1}$. Then a stable cyclic voltammetry (CV) curve was recorded at $50 \mathrm{mV} \mathrm{s}^{-1}$. The polarization curves for ORR were recorded in oxygen-saturated $0.1 \mathrm{M} \mathrm{HClO}_{4}$ solutions with or without $10 \mathrm{mM}$ citric acid at a scanning rate of $10 \mathrm{mV} \mathrm{s}^{-1}$ at $1600 \mathrm{rpm}$. The specific adsorption of citric acid was conducted in an Ar-saturated $0.05 \mathrm{M} \mathrm{H}_{2} \mathrm{SO}_{4}+10 \mathrm{~m} \mathrm{M}$ citric acid solution. The Cu UPD was conducted in Ar-saturated 0.05 $\mathrm{M} \mathrm{H}_{2} \mathrm{SO}_{4}+0.05 \mathrm{mM} \mathrm{CuSO}_{4}$ solutions with or without $0.1 \mathrm{M}$ citric acid at $5 \mathrm{mV} \mathrm{s}^{-1}$. The electrochemical deposition of $\mathrm{Pt}$ on $\mathrm{Pd} / \mathrm{C}$ was conducted in $\mathrm{Ar}$-saturated $0.05 \mathrm{M} \mathrm{H}_{2} \mathrm{SO}_{4}+1 \mathrm{mM}$ $\mathrm{K}_{2} \mathrm{PtCl}_{4}$ solutions with or without $0.1 \mathrm{M}$ citric acid by scanning from the open circuit potential (OCP) to $0.3 \mathrm{~V}$ at a scanning rate of $10 \mathrm{mV} \mathrm{s}^{-1}$.

In the synthesis of Pd@Pt/C on a RDE tip, a Cu UPD monolayer was deposited on the Pd/C electrode and then displaced by Pt in $0.05 \mathrm{M} \mathrm{H}_{2} \mathrm{SO}_{4}+1 \mathrm{mM} \mathrm{K}_{2} \mathrm{PtCl}_{4}$ solutions with citric acid concentrations varying from 0 to $0.2 \mathrm{M}$. The solution was stirred at $100 \mathrm{rpm}$. During the displacement, the OCP of the $\mathrm{Pd} / \mathrm{C}$ covered RDE tip was monitored with a leak-free $\mathrm{Ag} / \mathrm{AgCl}$ 
reference electrode. In the gram batch synthesis, $\mathrm{Pd} / \mathrm{C}$ nanoparticles were dispersed in an $\mathrm{Ar}$ saturated $50 \mathrm{mM} \mathrm{H}_{2} \mathrm{SO}_{4}+50 \mathrm{mM} \mathrm{CuSO}_{4}$ solution and stirred at $300 \mathrm{rpm}$. A custom reactor comprised a graphite sheet (the working electrode) at the bottom, carbon cloth (the counter electrode), and a leak-free Ag/AgCl reference electrode. The potential was held at approximately $0.37 \mathrm{~V}$ vs. Ag/AgCl to deposit a Cu UPD monolayer on Pd nanoparticles. Immediately upon completion of the $\mathrm{Cu} \mathrm{UPD}$, deaerated aqueous solutions of $10 \mathrm{mM} \mathrm{K}_{2} \mathrm{PtCl}_{4}$ with or without 0.2 $\mathrm{M}$ citric acid was added to the reactor in $2 \mathrm{~min}$. During the addition of the displacement solution and displacement reaction, the OCP of the graphite sheet was also recorded. Since nanoparticles in the synthesis suspension contacted with the graphite during stirring, the potential of the graphite was approximately the OCP of nanoparticles.

\subsection{Molecular Dynamics (MD) simulation}

The commercial software Material Studio (Version 6.1, Accelrys Inc, 2014) was used to perform MD simulations using the Discover module. The periodic canonical ensemble (NVT) with the COMPASS (Condensed-phase Optimized Molecular Potentials for Atomistic Simulation Studies) forcefield was used to calculate the potential energy of the system. ${ }^{21}$ This forcefield is particularly useful for this system because its parameters are derived from ab initio data, which can be applied to predict organic and inorganic materials in both gas-phases and condensed-phases. ${ }^{22}$ The Pd lattice $\left(a=b=c=3.88 \AA, \alpha=\beta=\gamma=90^{\circ}\right.$ ) was cleaved into the (111) slab surface with dimensions of $\sim 25 \times 25 \AA$ and thickness of $15 \AA$. To compare the interaction of the surface with a deposited monolayer of $\mathrm{Cu}$ or $\mathrm{Pt}$, the top surface of the $\mathrm{Pd}$ surface is replaced with $\mathrm{Cu}$ or $\mathrm{Pt}$ atoms (denoted as surfaces $\mathrm{Cu} / \mathrm{Pd}(111)$ and $\mathrm{Pt} / \mathrm{Pd}(111)$ respectively), such that they follow the (111) lattice packing system.

The adsorption of citric acid was simulated using a model that consists of 50 molecules placed randomly at a distance from the surface with a further $10 \AA$ vacuum space. The molecules will allow us to analyze its behavior, which can lead to an explanation of the stable Pt monolayer deposition on Pd nanoparticles. In order to simulate the replacement of $\mathrm{Cu}$ by Pt on the surface during the UPD process, the pure Pd(111) surface with seven atomic layers were replaced, such that the top layer becomes $\mathrm{Pt}$ atoms, the second layer becomes $\mathrm{Cu}$ atoms, and the bottom five layers remain as Pd atoms. The structure was firstly minimized, followed by replacing the forcefield of $\mathrm{Cu}$ from metallic $\mathrm{Cu}$ to $\mathrm{Cu}^{2+}$ ion. The simulation was run for 1000 ps with time-step 
of $1 \mathrm{fs}$ at room temperature ( $298 \mathrm{~K}$ ) in this study. The molecular model of the unit cell used in the MD simulation and the molecular structure of citric acid are shown in Figs. 2a and 2b, respectively.

The motion of the atoms became stable within 500 ps, which was used to calculate the diffusivity by measuring the slope from the plot of the mean squared displacement (MSD) against time. ${ }^{23}$ The diffusivity, $D_{\alpha}$, is given by:

$$
D_{\alpha}=\frac{1}{6 N_{\alpha}} \lim _{t \rightarrow \infty} \frac{d}{d t} \sum_{i=1}^{N_{\alpha}}\left\langle\left[\boldsymbol{r}_{i}(t)-\boldsymbol{r}_{i}(0)\right]^{2}\right\rangle
$$

where $N$ is the number of diffusive atoms, and $\boldsymbol{r}$ is the position vector of the atom in the system. Since the MSD value is averaged over the number of atoms, the equation simplifies to $D_{\alpha}=\mathrm{a} / 6$.

\section{Results and discussions}

We firstly conducted linear sweep voltammetry (LSV) measurements in order to investigate the effect of citric acid on deposition kinetics of Pt on the surfaces of Pd and Pt nanoparticles in Ar-saturated $0.05 \mathrm{M} \mathrm{H}_{2} \mathrm{SO}_{4}+1 \mathrm{mM} \mathrm{K}_{2} \mathrm{PtCl}_{4}$ solutions with or without $0.1 \mathrm{M}$ citric acid. The potential was scanned from the OCP to $0.3 \mathrm{~V}$. Without citric acid in the deposition solution, the Pt deposition on Pd/C started at the OCP ( $0.86 \mathrm{~V})$, as shown in Fig. 3 (black line). The current peak for the deposition was observed at $0.68 \mathrm{~V}$. By adding $0.1 \mathrm{M}$ citric acid in the solution, the onset potential of deposition did not change despite of slightly smaller currents between 0.86 and $0.76 \mathrm{~V}$ (red line). The result suggests that there is no complexation of Pt cations with citrate ions, otherwise the onset potential should be shifted according to the Nernst Equation. At potentials lower than $0.76 \mathrm{~V}$, the faradaic currents associated with Pt electrodeposition increased slightly with a weak current peak at $0.5 \mathrm{~V}$, which was $0.18 \mathrm{~V}$ more negative than that without citric acid. This result implies that the existence of citric acid interfered the Pt deposition on Pd surfaces.

To gain more insight in the specific adsorption of citric acid on Pd surfaces, CVs of Pd/C in Ar-saturated $0.05 \mathrm{M} \mathrm{H}_{2} \mathrm{SO}_{4}$ solutions with and without $10 \mathrm{mM}$ citric acid were compared. A typical CV for Pd/C ( 4 nm) without citric acid is shown in Fig. 4a (black line). The current peaks for hydrogen adsorption/desorption (H UPD) between 0.1 and $0.3 \mathrm{~V}$ were clearly observed. In the anodic scanning direction, the faradaic current associated with $\mathrm{OH}$ formation started to rise at $0.73 \mathrm{~V}$. With $10 \mathrm{mM}$ citric acid in the electrolyte (red line in Fig. 4a), the $\mathrm{H}$ UPD peaks were slightly narrowed. The narrowing of H UPD peaks suggests an overlapping of 
$\mathrm{H}$ and citrate anion adsorption in the $\mathrm{H}$ region. The $\mathrm{OH}$ adsorption was completely attenuated until at $0.8 \mathrm{~V}$, i.e., a $70 \mathrm{mV}$ shift compared with the $\mathrm{CV}$ measured in a sulfuric acid solution. The CV comparison was also conducted on $\mathrm{Pt} / \mathrm{C}(\sim 2.5 \mathrm{~nm})$, as shown in Fig. 4b. The similar narrowing of H UPD peaks and shifting to negative potentials, and delayed formation of $\mathrm{OH} / \mathrm{O}$ were also observed. Our results demonstrate that the adsorption of citrate are stronger than that of (bi)sulfate on both Pd and Pt surfaces. Similar effects of citric acid on CVs of Pd and Pt surfaces were found in $0.1 \mathrm{M} \mathrm{HClO}_{4}$ solutions (data not shown). Based on these CV studies, we may conclude that on both Pd and Pt surfaces, the $\mathrm{OH} / \mathrm{O}$ species start to form at potentials higher than $0.8 \mathrm{~V}$ in a citric acid containing $\mathrm{H}_{2} \mathrm{SO}_{4}$ solution, but with a much slower rate than in a citric acid free solution. The slower rate of oxide formation is due to the competition for surface sites between citric acid and oxygen. With a polished Pt polycrystalline electrode, these changes were even clearer (Fig. 4c). Especially in the H UPD region, the onset potential of $\mathrm{H}$ adsorption shifted by $\sim 80 \mathrm{mV}$ from $0.4 \mathrm{~V}$ to $0.32 \mathrm{~V}$. According to Attard et al. and Sun et al., citric acid had no effect on $\operatorname{Pt}(111)$ in the $\mathrm{H}$ UPD region, but significant co-adsorption was observed on $\mathrm{Pt}(100) .{ }^{24,25}$ The negative shifting and narrowing of H UPD peaks on Pt nanoparticles were also observed in their study. ${ }^{24}$ Fig. $4 \mathrm{a}$, b and c indicate that at potentials higher than $0.32 \mathrm{~V}, \mathrm{H}$ cannot be adsorbed on Pd and Pt surfaces due to the strong adsorption of citric acid. The determination of exact potential window that citric acid exists on these metal surfaces requires studies with more surface sensitive techniques such as in situ FTIR. The specific adsorption of citric acid also affects the ORR activity of Pt/C. As shown in Fig. 4d, the half-wave potential of the ORR curve of $\mathrm{Pt} / \mathrm{C}$ shifted to a negative direction by $\sim 65 \mathrm{mV}$ by adding $10 \mathrm{mM}$ citric acid in a $0.1 \mathrm{M} \mathrm{HClO}_{4}$ solution. The effect of the citric acid was more significant in the double layer than in the low or high potential regions. This might be due to a higher coverage of citrate anions on Pt surfaces in the double layer region. The adsorbed citrate anions can be easily removed from Pt surfaces by cycling the electrode in a clean $\mathrm{HClO}_{4}$ solution into a low potential region (hydrogen evolution region, for example). After cycling, the ORR activity can be fully covered (black dashed line in Fig. 4e).

Since the Cu-Pt displacement reaction involves the Cu UPD layer deposited on Pd substrate, it is also essential to understand the adsorption of citric acid on $\mathrm{Cu} / \mathrm{Pd}$ surface. Fig. $4 \mathrm{f}$ compares the $\mathrm{Cu}$ UPD on $\mathrm{Pd} / \mathrm{C}$ in Ar-saturated $0.05 \mathrm{M} \mathrm{H}_{2} \mathrm{SO}_{4}$ solutions with and without $0.1 \mathrm{M}$ citric acid. Without citric acid, the Cu UPD curve was consistent with the literature data. ${ }^{26} \mathrm{The} \mathrm{Cu}$ 
deposition was slightly delayed and the main deposition peak was broadened in a citric acid containing solution. The effect was more obvious in the stripping section, where the main stripping peak shifted positively by $50 \mathrm{mV}$ from $0.57 \mathrm{~V}$ to $0.62 \mathrm{~V}$. The completion of $\mathrm{Cu}$ stripping was also delayed by the similar amount. This result implies that the $\mathrm{Cu}$ monolayer is more stable in a sulfuric acid solution containing citric acid, which may be strongly adsorbed on $\mathrm{Cu} / \mathrm{Pd}$ surface.

The strong adsorption of citric acid on Cu may alter the kinetics of the Cu-Pt SLRR reaction. To support this hypothesis, the OCP change during the $\mathrm{Cu}-\mathrm{Pt}$ displacement reaction on a Pd/C thin film RDE tip was monitored. Fig. 5a shows the OCP (E) as a function of time (t) during the $\mathrm{Cu}$-Pt displacement in Ar-saturated $0.05 \mathrm{M} \mathrm{H}_{2} \mathrm{SO}_{4}+1 \mathrm{mM} \mathrm{K}_{2} \mathrm{PtCl}_{4}$ solutions containing citric acid with various concentrations. The displacement solution was stirred at $100 \mathrm{rpm}$ to minimize the mass transport effect of reactants. Without citric acid in the solution (black dashed line), the OCP of the RDE tip increased quickly and reached the plateau in $\sim 25 \mathrm{~s}$, indicating a very fast classic Cu-Pt SLRR reaction under this condition. ${ }^{27}$ By introducing $0.2 \mathrm{M}$ citric acid (a concentration similar to that used in the synthesis of Pd@Pt/C catalysts at gram batches), the OCP change rate was dramatically reduced and the potential did not reach the plateau until $50 \mathrm{~s}$ (blue line). These results clearly demonstrated that the existence of citric acid in the solution significantly changed the Cu-Pt SLRR kinetics. With a lower citric acid concentration (0.05 M), the shape of the E-t curve (red line) was only slightly changed as compared to the one without citric acid. Thus, the concentration of the citric acid also played a critical role in the SLRR reaction.

The effect of citric acid on the gram scale synthesis of Pd@Pt core-shell electrocatalysts was even more profound. As shown in Fig. 5b, without any citric acid in the solution, the OCP increased sharply and reached the plateau in $180 \mathrm{~s}$ (black dashed line) with a change rate about $2.44 \mathrm{mV} \mathrm{s}^{-1}$. By adding $0.2 \mathrm{M}$ citric acid in the solution, the shape of the E-t curve changed dramatically (blue line). There were two stages based on the change rate of the OCP. In the first $160 \mathrm{~s}$, the OCP increased linearly with a rate of $1.38 \mathrm{mV} \mathrm{s}^{-1}$. After that, the OCP increased at an even slower rate $\left(0.66 \mathrm{mV} \mathrm{s}^{-1}\right)$, which was only half of the first stage. The potential plateau was finally reached at $\sim 480 \mathrm{~s}$.

All the electrochemical data indicate that citric acid has a profound effect on the $\mathrm{Cu}-\mathrm{Pt}$ SLRR. In order to gain further understanding of the role of citric acid in improving the quality of 
the Pt shell, theoretical calculations of the interaction energies of citric acid on different surfaces and the simulation of the Cu-Pt displacement with/without citric acid were conducted. Fig. 6a compares the interaction energies of the citric acid on $\operatorname{Pd}(111), \mathrm{Cu} / \mathrm{Pd}(111)$, and $\mathrm{Pt} / \mathrm{Pd}(111)$ surfaces. The highly negative interaction energy for citric acid (50 molecules) indicates that it is relatively stable when the interface consists of Pd $\left(-1744.5 \mathrm{kcal} \mathrm{mol}^{-1}\right)$, Cu $\left(-1919.8 \mathrm{kcal} \mathrm{mol}^{-1}\right)$ and Pt (-2011.4 kcal mol $\left.{ }^{-1}\right)$. The minor interaction differences among the metals also shows that there is no preferential interaction that could weaken the structure during the UPD mechanism. The analysis of the adsorbed structures is shown in the radial distribution curve between the $\mathrm{O}$ in the $\mathrm{OH}$ and $\mathrm{C}=\mathrm{O}$ groups of citric acid (Fig. 6b). The average distance of the $\mathrm{O}(\mathrm{OH})$ and $\mathrm{O}(\mathrm{C}=\mathrm{O})$ atom in citric acid was both measured to be $2.95 \AA$, but the concentration of $\mathrm{OH}$ was relatively higher. This suggests that the alcohol group plays a more important role than the carboxylate group in the interaction mechanism.

Fig. 7 illustrates the model used to simulate the replacement of $\mathrm{Cu}$ with Pt. Experimentally, the $\mathrm{Pt}$ will replace $\mathrm{Cu}$ atoms one by one through random collision of the ions with nanoparticles. However, this process would be difficult due to limitations of changing forcefield and its ability to increase the model size and time in the computer program. Also, smaller versions of this systems were tested with water molecules including anions $\left(\mathrm{Cl}^{-}\right)$to balance the charges. However, they did not show significant interactions towards the surface, and were removed when the model size was expanded in the current study. The current model was created such that all Pt atoms had reached the surface of the nanoparticle and the UPD process was achieved spontaneously, where all $\mathrm{Cu}$ atoms were oxidized to $\mathrm{Cu}^{2+}$ ions.

Throughout the simulation, as shown in Fig. 8, it is possible to observe the rapid repulsion of $\mathrm{Cu}^{2+}$ ions, but the motion of Pt was relatively stable and adsorbed onto the Pd surface. After simulated time of 1000 ps, it is obvious that the system without citric acid did not deposit Pt atoms with a monolayer structure, but create empty spaces along the surface to form islands (Fig. 8a). The exposure of Pd surface and the formation of Pt clusters are possible factors that reduces catalytic activities of Pd@Pt/C toward oxygen reduction reactions. For the case with citric acid, the Pt surface was much more uniform with only a few missing atoms after 1000 ps of simulation (Fig. 7b). These results clearly demonstrated that the adsorption of citric acid on the modeled surfaces might be the main reason for the formation of a more uniform Pt monolayer on Pd cores. 
The process can also be illustrated graphically in the concentration profile of the atoms at various times to compare the systems without (Fig. 9a) and with (Fig. 9b) citric acid. Initially, all atoms were in the metallic state and exhibited uniform packing with the (111) structure. $\mathrm{Cu}$ and Pt were at a distance of $9 \AA$ and $11 \AA$, respectively. Once the reaction was initiated, the system without citric acid underwent Pt atoms being replaced and moving towards a closer distance at $25 \mathrm{ps}$, while $\mathrm{Cu}^{2+}$ ions were scattered throughout the system at distances up to $20 \AA$ with further simulated time of 1000 ps. However, when the same time frame of 25 ps are compared, the Pt atoms had a lower concentration when citric acid molecules were present, indicating that the $\mathrm{Pt}$ deposition process was relatively slower than the system without citric acid, which is consistent with experimental data. The concertation of Pt continued to increase at the $9 \AA$ region with further simulation time. This indicates the presence of more crystalline structure to form the Pt monolayer on the Pd surface.

The motion of the formed $\mathrm{Cu}^{2+}$ ions can also be analyzed from the plot of its diffusivity (or mean squared displacement) over a period of time (Fig. 10). The much larger value for $\mathrm{Cu}^{2+}$ without the presence of citric acid than with citric acid indicates that $\mathrm{Cu}^{2+}$ of the former has a high probability to leave the surface and is able to reach a further distance within a shorter period of time. In the case with citric acid, it is able to increase the stability of $\mathrm{Cu}^{2+}$ by compressing the surface from strong interactions. The slower diffusion rate of $\mathrm{Cu}^{2+}$ can reduce the amount of defects as it allows Pt atoms to slowly replace their positions, where a rapid diffusion of $\mathrm{Cu}^{2+}$ from the surface can cause more Pt monolayer regions to be shifted upwards to form a secondary layer or clusters on the Pd surface.

The behavior of citric acid molecules on the Pt/Pd surface can be observed over a period of 1000 ps, as seen in Fig. 11. Initially, citric acid absorbed on the Pt surface formed a dense layer at the interface corresponding to $\sim 14 \AA$ in cell position. During the simulation, $\mathrm{Cu}^{2+}$ atoms were repelled from the surface, pushing the citric acid layer upwards. As seen at the time frame of 10 to $500 \mathrm{ps}, \mathrm{Cu}^{2+}$ ions could force the citric acid layer to shift slightly upwards by $\sim 1 \AA$, such that the atomic concentration at the interface decreased and lost its densely packed layer. However, the formation of the Pt monolayer is differentiated by the strong interaction with the $\mathrm{Pt} / \mathrm{Pd}$ surface. As seen previously, the Pt/Pd surface had the strongest interaction with the citric acid molecules. After most of $\mathrm{Cu}$ atoms were replaced by Pt atoms and entered into the solution, the citric acid molecules will move towards the new Pt monolayer that have stabilized, which shifted 
the atomic concentration by $1.3 \AA$, from 14.0 to $12.7 \AA$, the approximate length of one monolayer. After 1000 ps, the dense packing of the citric acid layer could not recover quickly over the long period of time. This shows that a surfactant with a strong interaction with the surface can stabilize the motion of Pt atoms, such that it compresses the layer to slow down the $\mathrm{Cu}^{2+}$ and $\mathrm{Pt}$ from vibrating too quickly, which allows $\mathrm{Pt}$ to form a secondary layer.

\section{Conclusion}

The role of citric acid in controlling the uniformity of Pt monolayers on Pd was studied by electrochemical techniques and theoretical approaches. It was found that citric acid strongly adsorbs on $\mathrm{Pd}, \mathrm{Pt}, \mathrm{Cu} / \mathrm{Pd}$ and $\mathrm{Pt} / \mathrm{Pd}$ surfaces, especially in the double layer region in acid solutions, according to their CVs in citric acid containing solutions. The strong interactions between the citric acid and surfaces of $\mathrm{Pt}$ and $\mathrm{Cu} / \mathrm{Pd}$ were further confirmed by the electrodeposition of Pt and delayed stripping of Cu UPD layer on Pd surfaces, respectively. The strong adsorption of citric acid slowed down the Cu-Pt displacement reaction as indicated by the decrease of the rising rate of the open circuit potential during the reaction. This phenomenon might be caused by the fact that Pt atoms deposited on the Pd surface in the early stage of the $\mathrm{Cu}-\mathrm{Pt}$ displacement reaction were covered by a dense layer of citric acid in the potential range where the reaction occurred. As a result, further deposition of Pt on the already existing Pt atoms covered by a citric acid layer to form 3D clusters was prohibited. The Cu-Pt SLRR process was further studied using molecular dynamics simulations with a simplified model. The results confirmed that citric acid could interact strongly with $\mathrm{Pd}, \mathrm{Cu} / \mathrm{Pd}$, and $\mathrm{Pt} / \mathrm{Pd}$ surfaces. The main characteristics of such strong interaction most likely arises from the $\mathrm{OH}$ groups in the citric acid molecule.

\section{Acknowledgment}

Authors would like to thank the financial support from the Research Grant Council of the Hong Kong Special Administrative Region (IGN13EG05 and 26206115) and a startup fund from the Hong Kong University of Science and Technology. The work at the Brookhaven National Laboratory was supported by the U.S. Department of Energy, Office of Basic Energy Sciences, under Contract No. DE-AC02-98CH10886. S.R. Brankovic acknowledges support from private funding sources and NSF Chemistry Program under contract \#0955922. 


\section{References}

1. R. R. Adzic, Electrocatalysis, 3, 163 (2012).

2. R. R. Adzic, J. Zhang, K. Sasaki, M. B. Vukmirovic, M. Shao, J. X. Wang, A. U. Nilekar, M. Mavrikakis, J. A. Valerio and F. Uribe, Top. Catal., 46, 249 (2007).

3. S. Ball, in Electrocatalysis in Fuel Cells: A Non- and Low-Platinum Approach, M. Shao Editor, Springer, London (2013).

4. $\quad$ M. Shao, Q. Chang, J.-P. Dodelet and R. Chenitz, Chem. Rev., 116, 3594 (2016).

5. M. Shao, B. H. Smith, S. Guerrero, L. Protsailo, D. Su, K. Kaneko, J. H. Odell, M. P. Humbert, K. Sasaki, J. Marzullo and R. M. Darling, Phys. Chem. Chem. Phys., 15, 15078 (2013).

6. M. H. Shao, K. Shoemaker, A. Peles, K. Kaneko and L. Protsailo, J. Am. Chem. Soc., 132, 9253 (2010).

7. K. Sasaki, H. Naohara, Y. Cai, Y. M. Choi, P. Liu, M. B. Vukmirovic, J. X. Wang and R. R. Adzic, Angew. Chem. Int. Ed., 49, 8602 (2010).

8. S.-I. Choi, M. Shao, N. Lu, A. Ruditskiy, H.-C. Peng, J. Park, S. Guerrero, J. Wang, M. J. Kim and Y. Xia, ACS Nano, 8, 10363 (2014).

9. J. Park, L. Zhang, S.-I. Choi, L. T. Roling, N. Lu, J. A. Herron, S. Xie, J. Wang, M. J. Kim, M. Mavrikakis and Y. Xia, ACS Nano, 9, 2635 (2015).

10. G. Zhang, Z.-G. Shao, W. Lu, H. Xiao, F. Xie, X. Qin, J. Li, F. Liu and B. Yi, J. Phys. Chem. C, 117, 13413 (2013).

11. R. Choi, S.-I. Choi, C. H. Choi, K. M. Nam, S. I. Woo, J. T. Park and S. W. Han, Chemistry - A European Journal, 19, 8190 (2013).

12. X. Wang, S.-I. Choi, L. T. Roling, M. Luo, C. Ma, L. Zhang, M. Chi, J. Liu, Z. Xie, J. A. Herron, M. Mavrikakis and Y. Xia, Nat. Commun., 6, 7594 (2015).

13. J. L. Zhang, M. B. Vukmirovic, Y. Xu, M. Mavrikakis and R. R. Adzic, Angew. Chem. Int. Ed., 44, 2132 (2005).

14. X. Wang, Y. Orikasa, Y. Takesue, H. Inoue, M. Nakamura, T. Minato, N. Hoshi and Y. Uchimoto, J. Am. Chem. Soc., 135, 5938 (2013).

15. M. Shao, G. He, A. Peles, J. H. Odell, J. Zeng, D. Su, J. Tao, T. Yu, Y. Zhu and Y. Xia, Chem. Commun., 49, 9030 (2013). 
16. S. L. Knupp, M. B. Vukmirovic, P. Haldar, J. A. Herron, M. Mavrikakis and R. R. Adzic, Electrocatalysis, 1, 213 (2010).

17. M. Shao, A. Peles and K. Shoemaker, Nano Lett., 11, 3714 (2011).

18. C. Thambidurai, D. K. Gebregziabiher, X. Liang, Q. Zhang, V. Ivanova, P.-H. Haumesser and J. L. Stickney, J. Electrochem. Soc., 157, D466 (2010).

19. M. Humbert, B. Smith, Q. Wang, S. Ehrlich and M. Shao, Electrocatalysis, 3, 298 (2012).

20. S. Khateeb, S. Guerreo, D. Su, R.M. Darling, L.V. Protsailo and M. H. Shao, J. Electrochem. Soc., submitted (2016).

21. H. Sun, J. Phys. Chem. B, 102, 7338 (1998).

22. H. Sun, P. Ren and J. R. Fried, Comput. Theor. Polym. Sci., 8, 229 (1998).

23. J. Yue, X. Jiang and A. Yu, J Nanopart Res, 13, 3961 (2011).

24. G. A. Attard, J.-Y. Ye, P. Jenkins, F. J. Vidal-Iglesias, E. Herrero and S.-G. Sun, J. Electroanal. Chem., 688, 249 (2013).

25. D. Chen, J. Ye, C. Xu, X. Li, J. Li, C. Zhen, N. Tian, Z. Zhou and S. Sun, Science China Chemistry, 55, 2353 (2012).

26. M. Shao, J. Odell, M. Humbert, T. Yu and Y. Xia, J. Phys. Chem. C, 117, 4172 (2013).

27. D. Gokcen, S.-E. Bae and S. R. Brankovic, Electrochim. Acta, 56, 5545 (2011). 


\section{Figure Captions}

Fig. 1. A schematic diagram of the formation of the Pt shell on a Pd substrate involving the CuUPD-mediated method with and without citric acid.

Fig. 2. a) The molecular model of the unit cell used in the MD simulation to determine the adsorption energy of citric acid on the (Pt or $\mathrm{Cu}$ ) monolayer deposited Pd surface; and b) the molecular structure of citric acid.

Fig. 3. Electrochemical deposition curves of Pt on $\mathrm{Pd} / \mathrm{C}$ in Ar-saturated $50 \mathrm{mM} \mathrm{H}_{2} \mathrm{SO}_{4}+1 \mathrm{mM}$ $\mathrm{K}_{2} \mathrm{PtCl}_{4}$ solutions without (black line) and with (red line) $0.1 \mathrm{M}$ citric acid at a scanning rate of $10 \mathrm{mV} \mathrm{s}^{-1}$.

Fig. 4. Comparisons of cyclic voltammograms for $\mathrm{Pd} / \mathrm{C}$ a), $\mathrm{Pt} / \mathrm{C}$ b) supported on a glassy carbon electrode, and c) a polycrystalline Pt electrode in Ar-saturated $50 \mathrm{mM} \mathrm{H}_{2} \mathrm{SO}_{4}$ solutions without (black line) and with $10 \mathrm{mM}$ citric acid (red line) at a scanning rate of $50 \mathrm{mV} \mathrm{s}^{-1}$. d) Polarization curves for $\mathrm{Pt} / \mathrm{C}$ supported on a glassy carbon electrode in $\mathrm{O}_{2}$-saturated $0.1 \mathrm{M} \mathrm{HClO}_{4}$ solutions without (black line) and with $10 \mathrm{mM}$ citric acid (red line) at a scanning rate of $10 \mathrm{mV} \mathrm{s}^{-1}$. e) Comparisons of polarization curve for $\mathrm{Pt} / \mathrm{C}$ in an $\mathrm{O}_{2}$-saturated $0.1 \mathrm{M} \mathrm{HClO}_{4}$ solution before citric acid adsorption (black line), and after adsorption in a $0.1 \mathrm{M} \mathrm{HClO}_{4}+10 \mathrm{mM}$ citric acid solution for $60 \mathrm{~s}$ and subsequent cycling in clean a $0.1 \mathrm{M} \mathrm{HClO}_{4}$ solution between $-0.05 \mathrm{~V}$ and $1.2 \mathrm{~V}$ (black dashed line). f) $\mathrm{Cu}$ underpotential deposition curves for $\mathrm{Pd} / \mathrm{C}$ in $50 \mathrm{mM} \mathrm{H}_{2} \mathrm{SO}_{4}+50 \mathrm{mM}$ $\mathrm{CuSO}_{4}$ solutions without (black), and with (red line) $0.1 \mathrm{M}$ citric acid at a scanning rate of $5 \mathrm{mV}$ $\mathrm{S}^{-1}$.

Fig. 5. a) The OCP changes for $\mathrm{Pd} / \mathrm{C}$ covered with a $\mathrm{Cu}$ monolayer in $50 \mathrm{mM} \mathrm{H}_{2} \mathrm{SO}_{4}+1 \mathrm{mM}$ $\mathrm{K}_{2} \mathrm{PtCl}_{4}$ solutions containing citric acid with various concentrations: $0 \mathrm{mM}$ (black dashed line), $50 \mathrm{mM}$ (red line), and $200 \mathrm{mM}$ (blue line); b) the OCP changes for the graphite electrode in the gram scale synthesis in the $50 \mathrm{mM} \mathrm{H}_{2} \mathrm{SO}_{4}+50 \mathrm{mM} \mathrm{CuSO}_{4}$ solutions during the displacement reaction when $50 \mathrm{mM} \mathrm{H}_{2} \mathrm{SO}_{4}+10 \mathrm{mM} \mathrm{K}_{2} \mathrm{PtCl}_{4}$ solutions without (black dashed line) and with (blue line) $0.2 \mathrm{M}$ citric acid were used, respectively.

Fig. 6. a) Column graph of the interaction energy ( $\mathrm{kcal} \mathrm{mol}^{-1}$ ) of citric acid (50 molecules) on pristine, and $\mathrm{Cu}$ and Pt monolayer modified Pd(111) surfaces; b) plot of radial distribution g(r) of various types of oxygen atoms with Pd atoms for the citric acid on $\operatorname{Pd}(111)$ systems.

Fig. 7. Molecular model of replacement of $\mathrm{Cu}$ with Pt at 0 ps and 1000 ps. 
Fig. 8. Top view of the model at initial (0 ps) and final (1000 ps) without a) and with b) citric acid.

Fig. 9. Concentration profiles of $\mathrm{Pd}, \mathrm{Cu}$ and $\mathrm{Pt}$ during the displacement reaction without and with citric acid at 0 ps, 25 ps, 200 ps, and 1000 ps.

Fig. 10. Plot of the diffusivity of $\mathrm{Cu}^{2+}$ ions during the displacement process with and without citric acid.

Fig. 11. Concentration profiles of citric acid during the replacement of $\mathrm{Cu}$ with $\mathrm{Pt}$ on $\mathrm{Pd}(111)$ at various times in the MD simulation. 


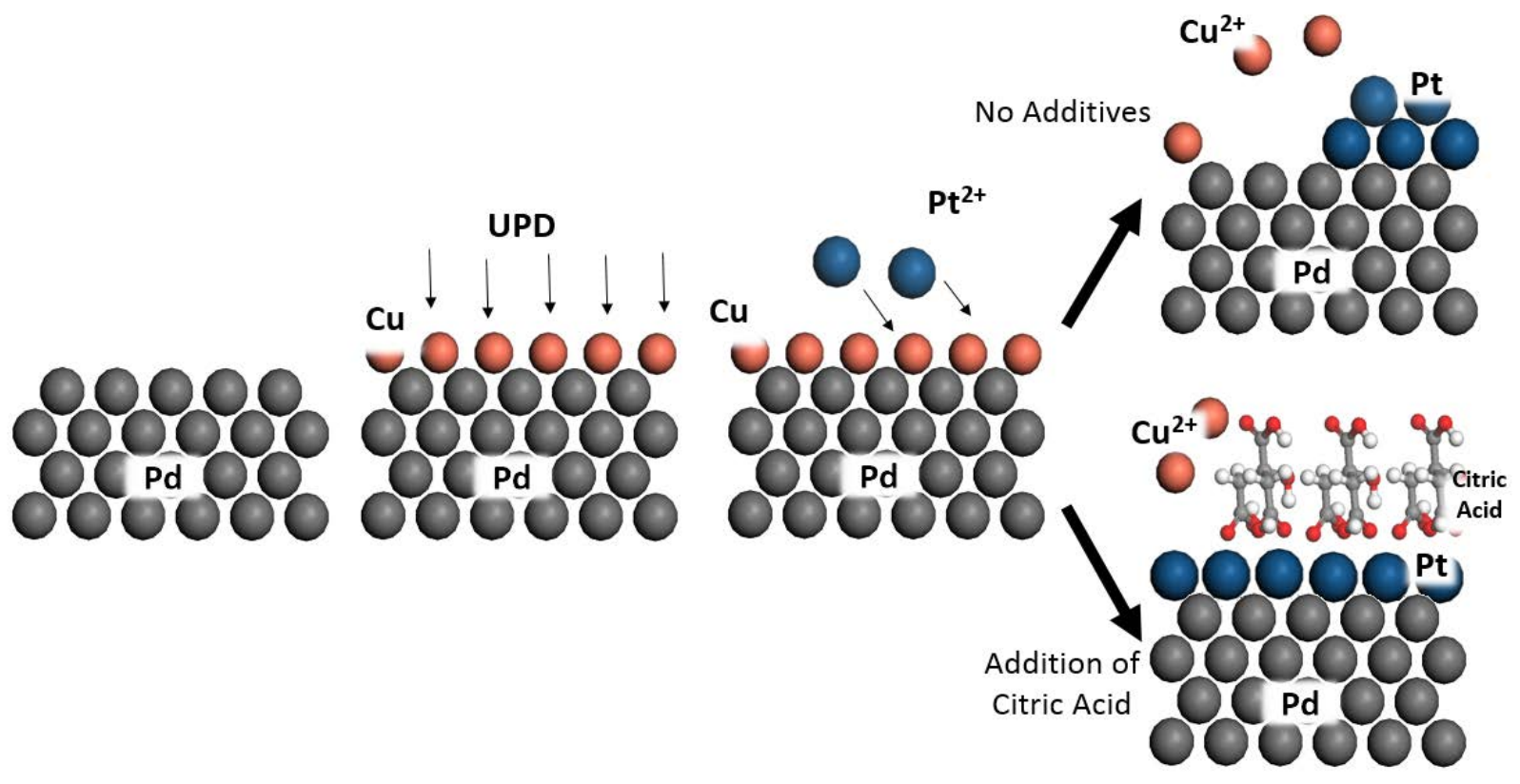

Fig. 1. 


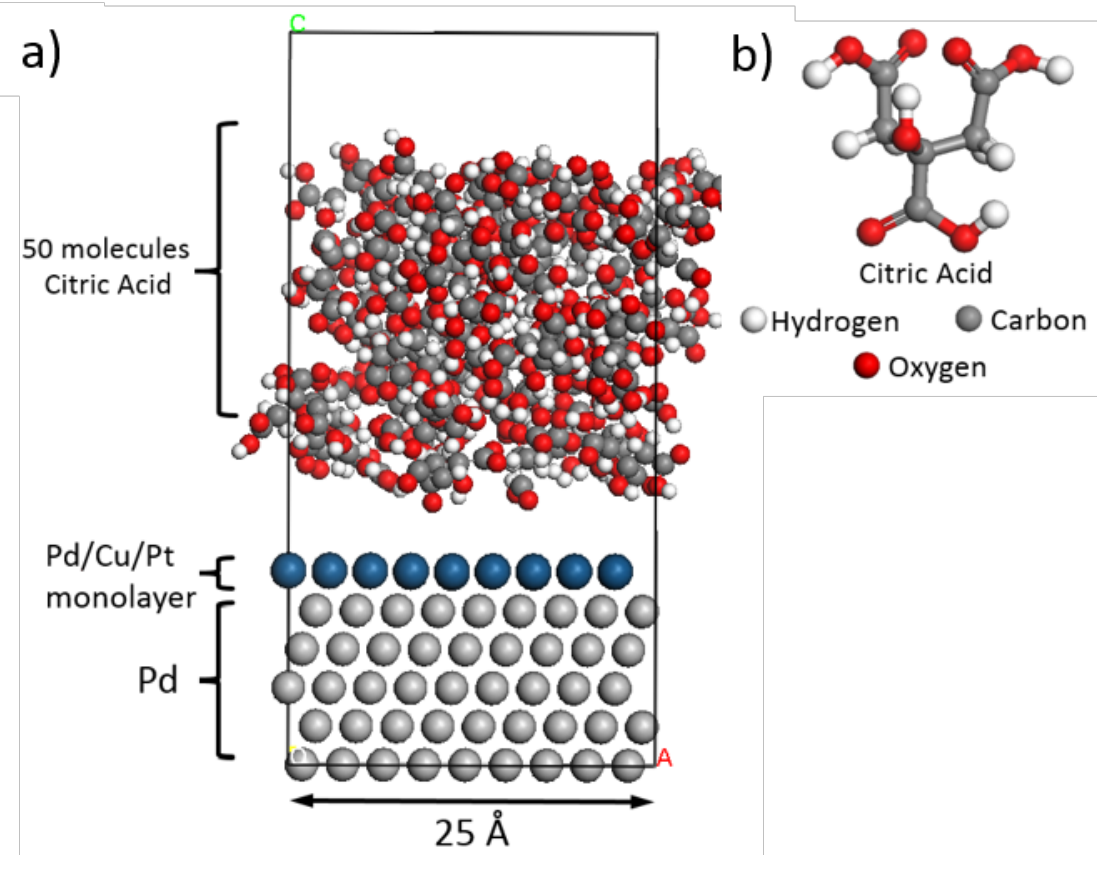

Fig. 2 


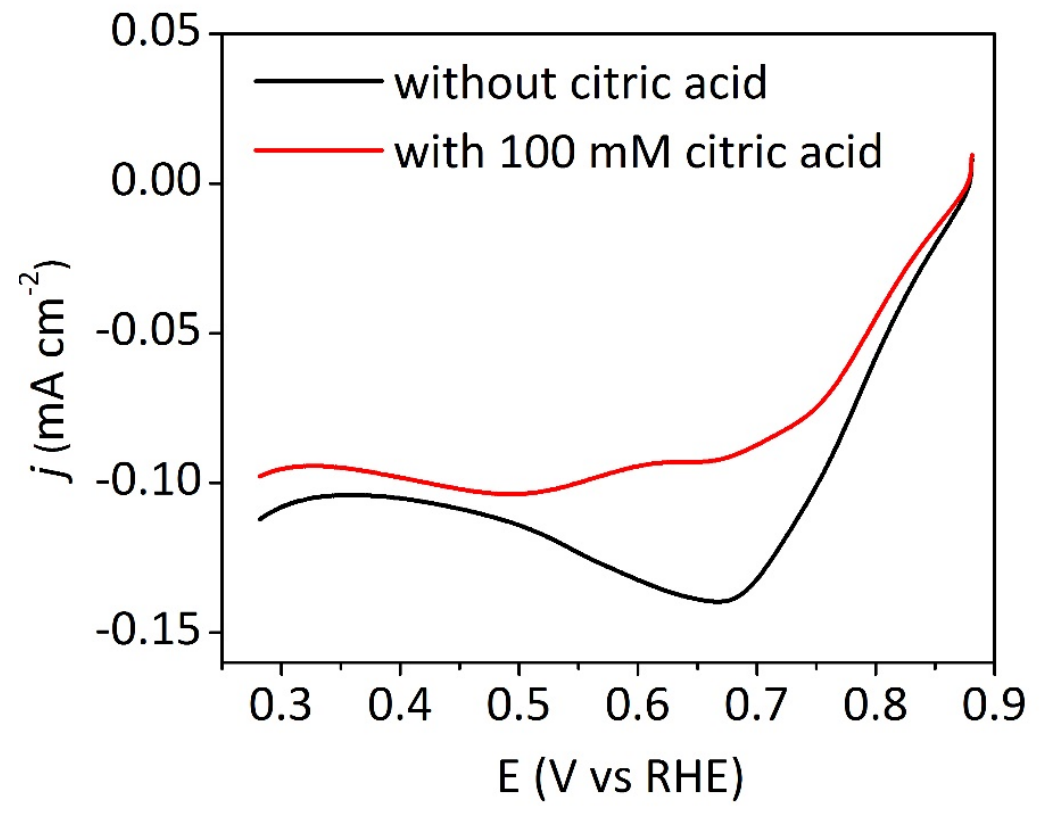

Fig. 3. 

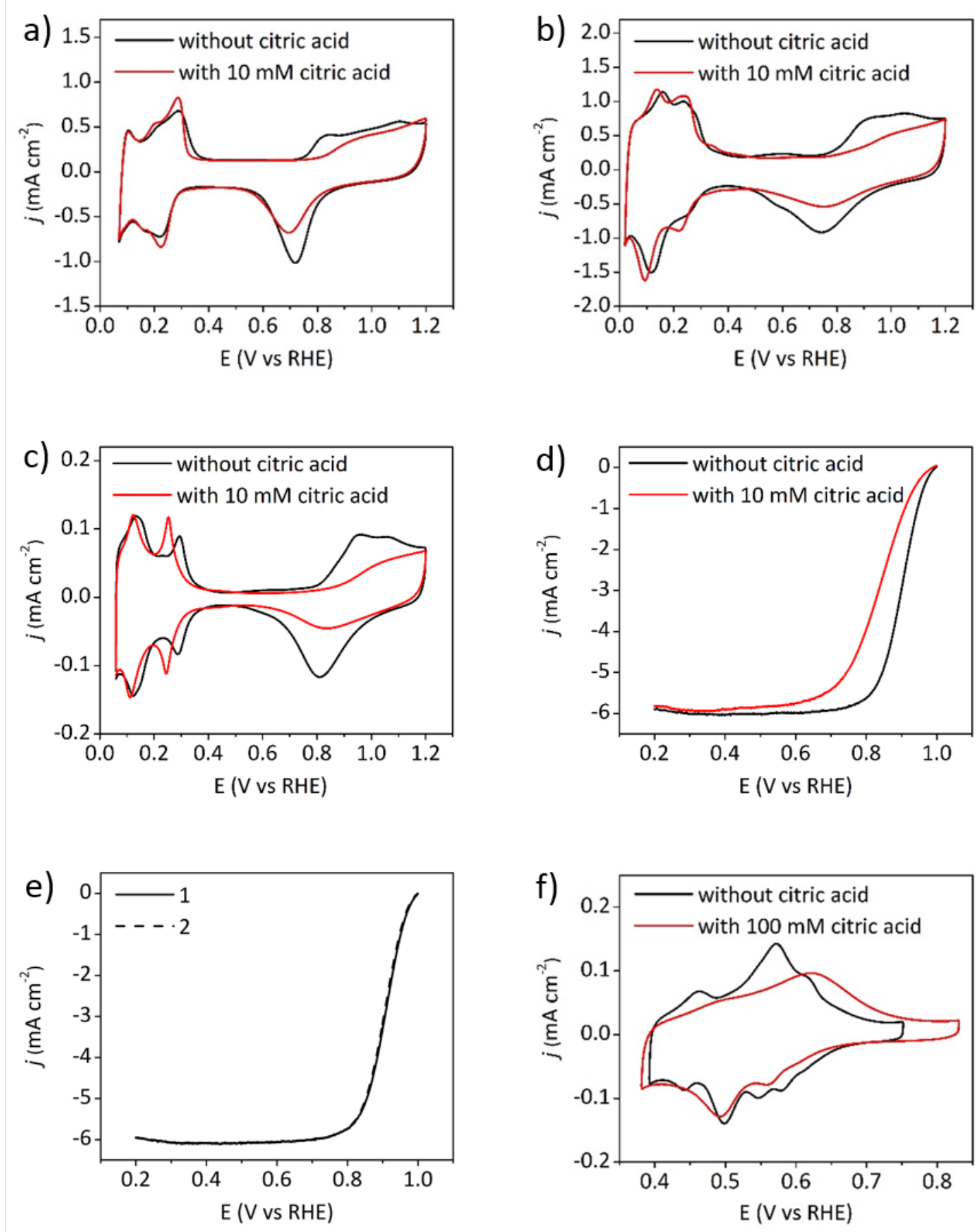

Fig. 4 

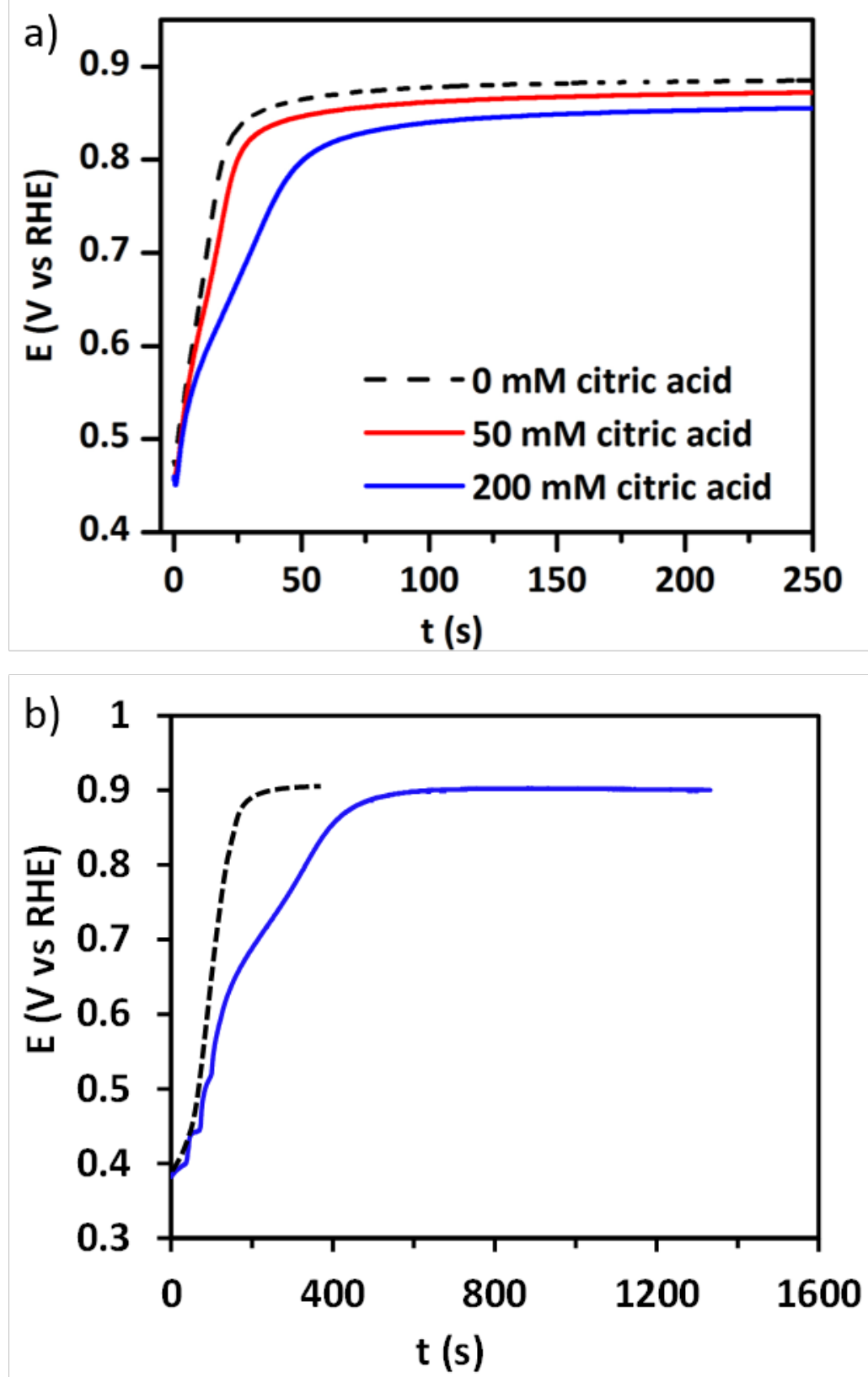

Fig. 5 

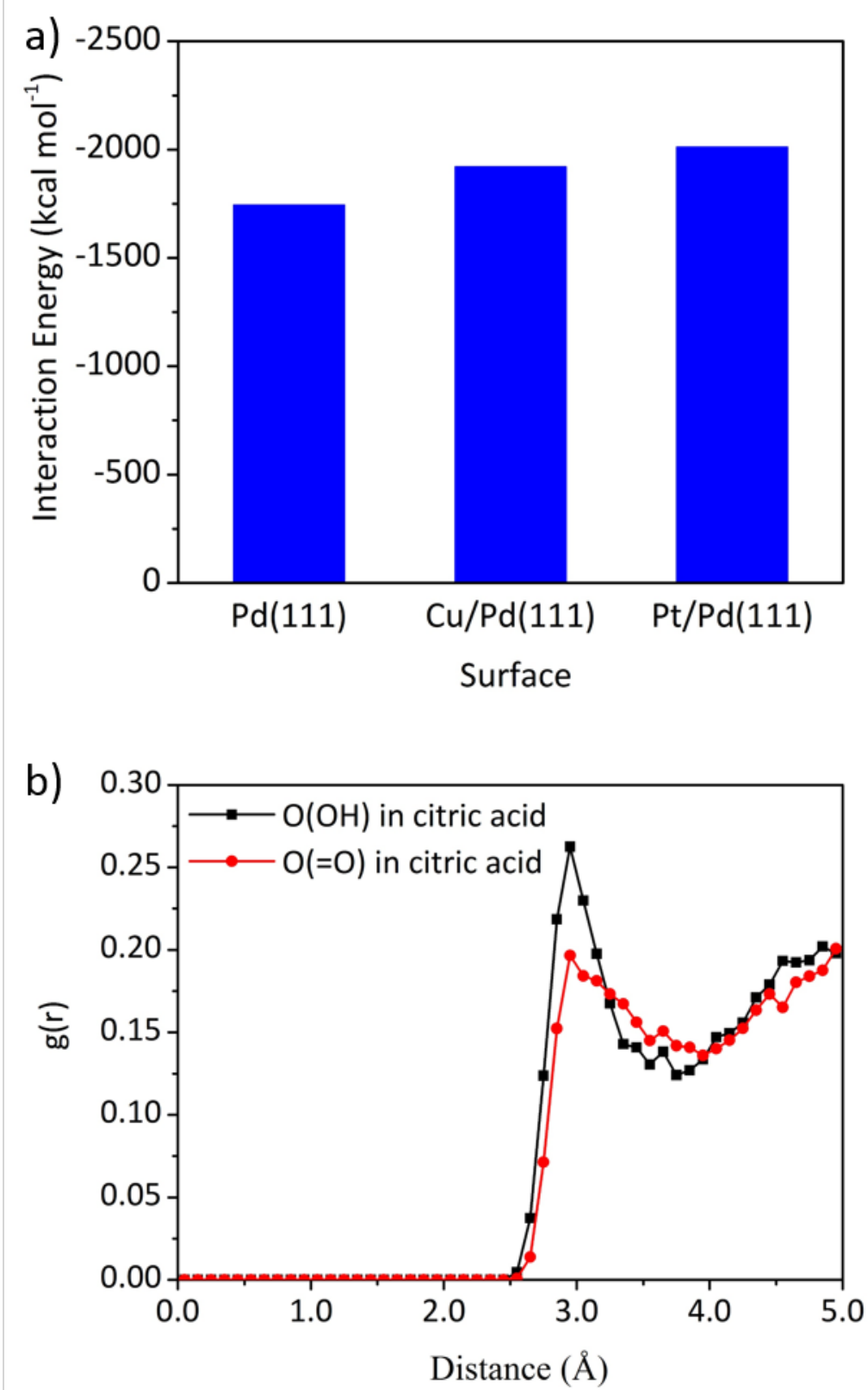

Fig. 6 


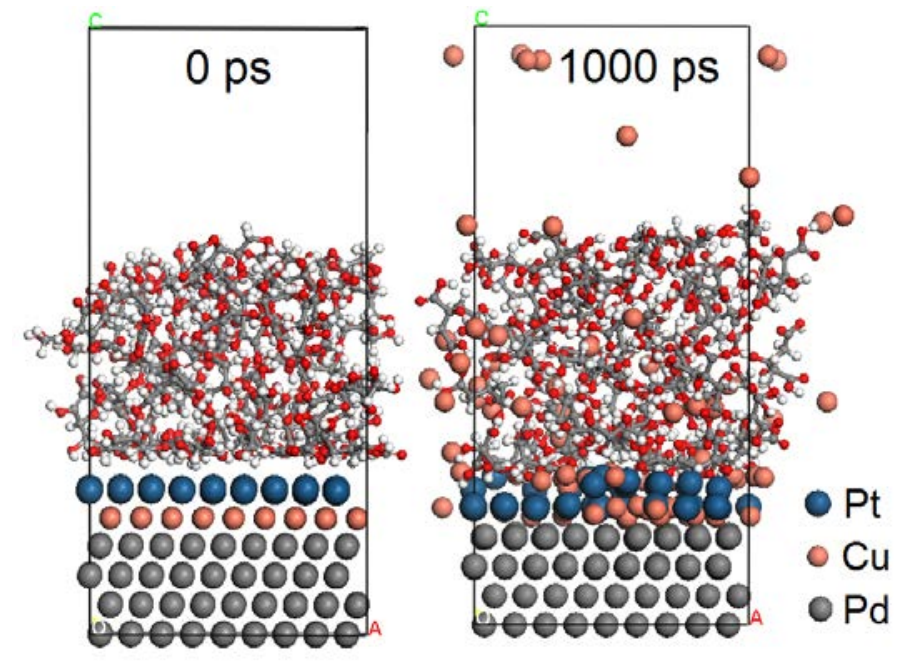

Fig.7 
a) without citric acid

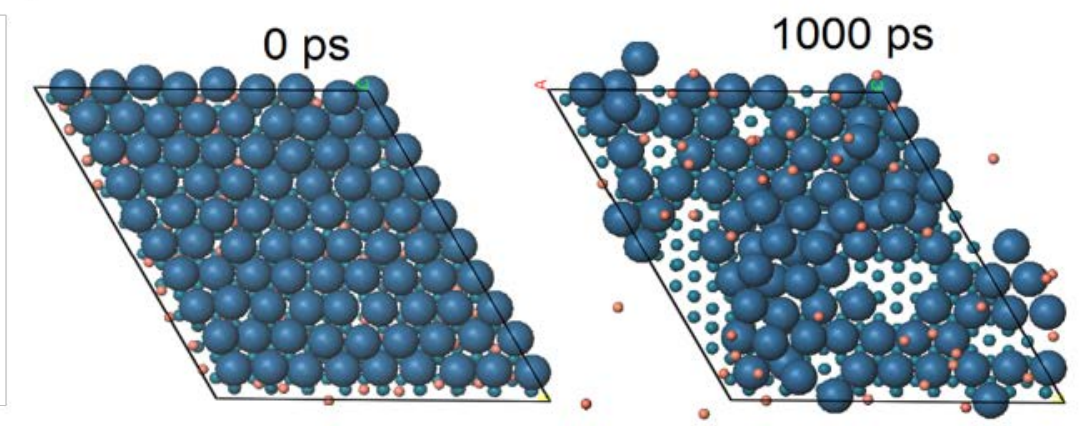

b) with citric acid

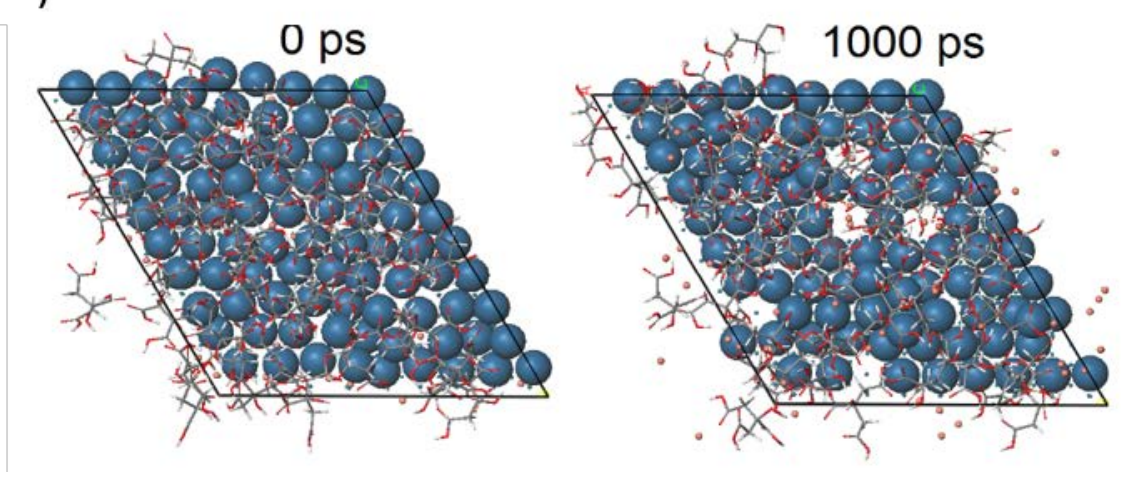

Fig.8 


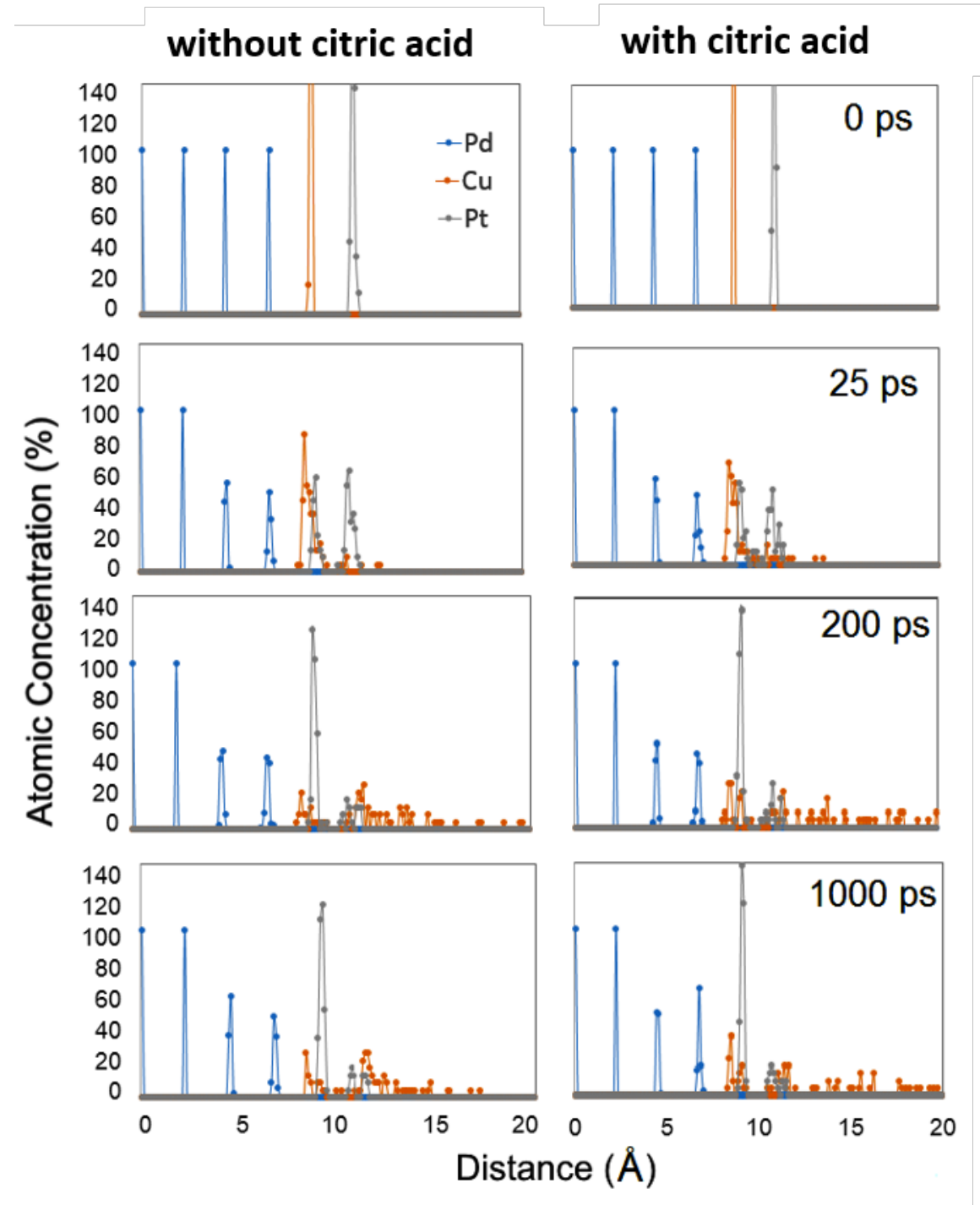

Fig.9 


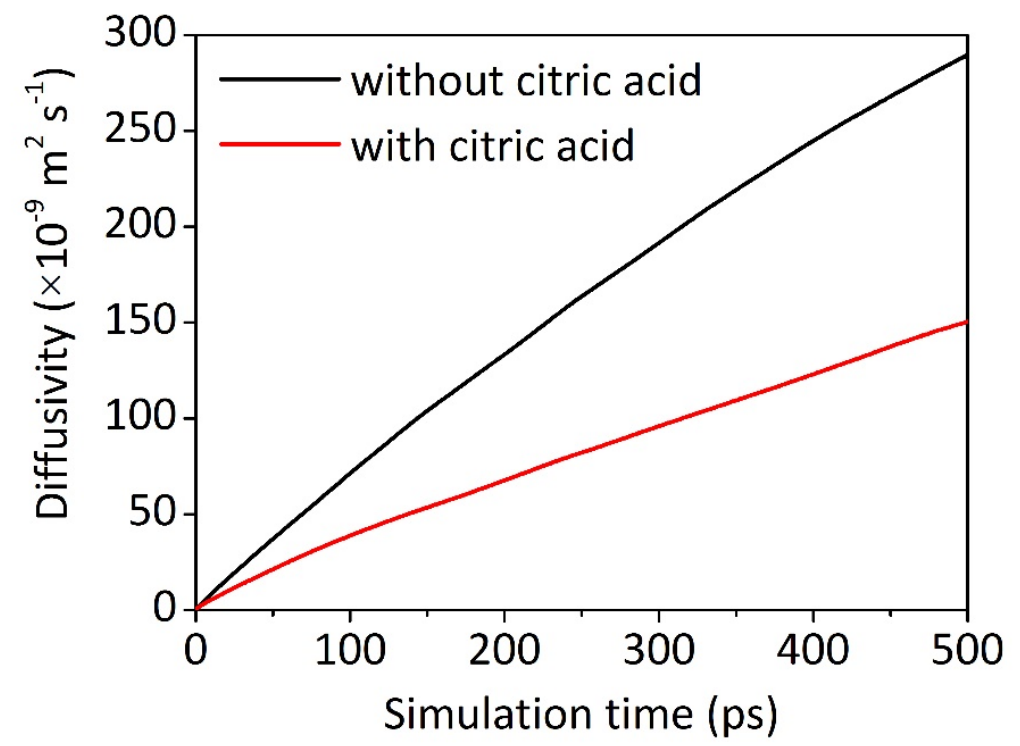

Fig. 10 


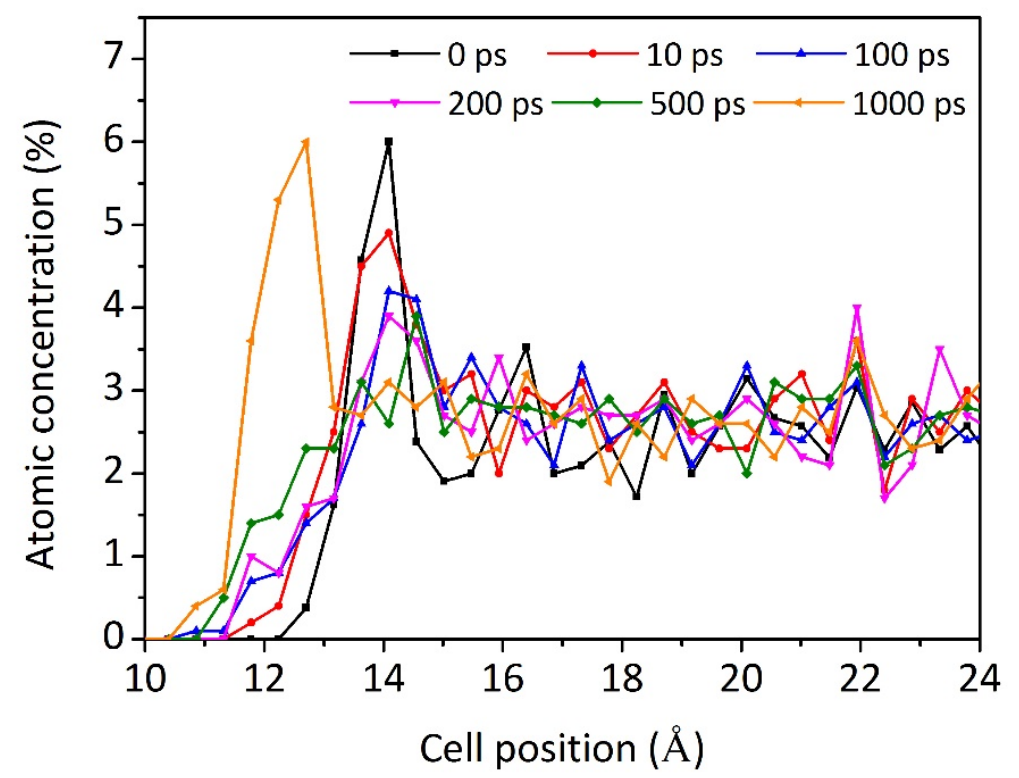

Fig. 11 